\title{
Air-sea gas transfer velocity estimates from the Jason-1 and TOPEX altimeters: Prospects for a long-term global time series
}

\author{
David M. Glover*, Nelson M. Frew, and Scott J. McCue \\ Department of Marine Chemistry and Geochemistry, Woods Hole Oceanographic \\ Institution, Woods Hole, MA 02543
}

\begin{abstract}
Estimation of global and regional air-sea fluxes of climatically important gases is a key goal of current climate research programs. Gas transfer velocities needed to compute these fluxes can be estimated by combining altimeter-derived mean square slope with an empirical relation between transfer velocity and mean square slope derived from field measurements of gas fluxes and small-scale wave spectra (Frew et al., 2004). We previously reported initial results from a dual-frequency (Ku- and C-band) altimeter algorithm (Glover et al., 2002) for estimating the air-sea gas transfer velocity $(k)$ from the mean square slope of short wind waves (40-100 rad/m) and derived a six-year time series of global transfer velocities based on TOPEX observations. Since the launch of the follow-on altimeter Jason-1 in December 2001 and commencement of the TOPEX/Jason-1 Tandem Mission, we have extended this time series to 12 years, with improvements to the model parameters used in algorithm and using the latest corrected data releases. The prospect of deriving multi-year and interdecadal time series of gas transfer velocity from TOPEX, Jason-1, and followon altimeter missions depends on precise intercalibration of the normalized backscatter. During the Tandem Mission collinear phase, both satellites followed identical orbits with a mere 73-second time separation. The resulting collocated, near-coincident normalized radar backscatter $\left(\sigma^{\circ}\right)$ data from both altimeters present a unique opportunity to intercalibrate the two instruments, compare derived fields of transfer velocity, and estimate the precision of the algorithm. Initial results suggest that the monthly gas transfer velocity fields generated from the two altimeters are very similar. Comparison of along-track Ku-band and C-band $\sigma^{\circ}$ during the collinear phase indicates that observed discrepancies are due primarily to small offsets between TOPEX and Jason- $1 \sigma^{\circ}$. The Jason- $1 k$ values have an apparent bias of $4 \%$ relative to TOPEX, while the precision estimated from the two observation sets is $5-7 \%$ and scales with $k$. The resultant long-term, global, mean $k$ is $16 \mathrm{~cm} / \mathrm{h}$.
\end{abstract}

Key words:

gas exchange, altimetry, mean square slope 


\section{Introduction}

The gas transfer velocity $(k)$ is recognized as a critical variable in global carbon cycle research, because it it so poorly known. Simply allowing $k$ to be an univariate function of wind speed at 10 meters $\left(k=f\left(U_{10}\right)\right)$ is considered inadequate for global quantification of the flux of $\mathrm{CO}_{2}\left(\mathrm{~F}_{\mathrm{CO}_{2}}\right)$ between the ocean and atmosphere (Wallace, 1995; DeGrandpre et al., 2002; Olsen et al., 2005). This inadequacy is due to other factors that also influence gas transfer rates for example, presence of surface films, variable fetch, boundary layer stability, wave-wave interactions and wave breaking (Frew et al., 2004). An alternate approach is to directly measure sea surface roughness and use this measurement as a proxy for the near-surface turbulence that drives gas exchange.

Using this approach, an algorithm has been developed (Glover et al., 2002; Frew et $a l ., 2006)$ that allows for remote sensing of the gas transfer velocity. The algorithm uses the mean square slope $\left(\left\langle s^{2}\right\rangle\right)$, of the sea surface capillary - gravity waves, as a proxy for near surface turbulence (Bock et al., 1999; Frew et al., 2004) resulting in a relationship $k=f\left(\left\langle s^{2}\right\rangle\right)$. This relationship is combined with another that relates $\left\langle s^{2}\right\rangle$ to the dual-frequency radar backscatter (Ku- and C-band) of the TOPEX altimeter $\left(\left\langle s^{2}\right\rangle=f\left(\sigma_{\mathrm{Ku}}^{\circ}, \sigma_{\mathrm{C}}^{\circ}\right)\right)$. This latter function exploits the dual-frequency nature of the TOPEX data and isolates mean square slope contributions from short wind waves demonstrated to be strongly correlated with gas transfer rate (Frew et al., 2004). The new algorithm produces monthly, global $\left(65^{\circ} \mathrm{S}-65^{\circ} \mathrm{N}\right)$ gridded fields of gas transfer velocity at $2.5^{\circ} \times 2.5^{\circ}$ resolution (Frew et al., 2006).

Two dual frequency altimeter missions have been launched to date: TOPEX in August 1992 and Jason-1 in December 2001. Jason-1 operates successfully in the orbit formerly occupied by TOPEX, which came to the end of its operation due to a reaction wheel failure in October 2005. TOPEX was designed with redundant altimeters onboard (Side-A and Side-B). By February 1999, the Side-A altimeter had deteriorated to the point that it was no longer returning reliable data based on significant wave height diagnostics (Quartly, 2000) and the Side-B altimeter was brought online. The current time series of altimetry data is thus derived from three altimeters: TOPEX Side-A, TOPEX Side-B, and Jason-1. This paper will discuss how we have ensured that our algorithm operates consistently across all three altimeters and provide initial results from the 12-year time series now available. The joint U.S. and France Ocean Surface Topography (OST) project currently has a followon dual frequency mission (Jason-2) planned for launch in April 2008. Therefore, the prospects for a long-term (decadal to multi-decadal), consistent, global time series of $k$ appear to be excellent.

\footnotetext{
* Corresponding author address: Mail Stop \#25, WHOI, Woods Hole, MA 02543

Email addresses: dglover@whoi .edu (David M. Glover), nfrew@whoi . edu

(Nelson M. Frew), smccue@whoi . edu (Scott J. McCue).

URL: http://w3eos. whoi.edu/ david/ktrans/(David M. Glover).
} 


\section{Methods}

\section{$2.1 \quad$ Data}

This study uses the GDR (Geophysical Data Record) Correction Product, version c (GCPc) TOPEX (cycles 017-452) and the GDR Jason-1 (cycles 001-109) data products (Picot et al., 2003) available from NASA's Jet Propulsion Laboratory, Physical Oceanography Distributed Active Archive Center (PO.DAAC). Data quality flags and value bounds are applied to the $\sigma^{\circ}$ values extracted following Benada (1997) and Picot et al. (2003) to eliminate spurious data points as well as data over land or ice. Rain events are filtered out of both data streams by application of the rain flag algorithm of Tournadre and Morland (1997). The data are then splined and resampled at a $7 \mathrm{~km}$ spacing to place both data streams on a common latitudinal grid with the native $1 \mathrm{~Hz}$ sampling frequency. These $\sigma^{\circ}$ are then processed with our algorithm and the resultant $k$ are binned into a $2.5^{\circ}$, one month grid. During the last step, additional independent land and ice masks are applied to remove any edge effects not removed by the standard data handling procedures of Benada (1997) and Picot et al. (2003).

\subsection{Algorithm}

The details of the development, calibration, and verification of the algorithm that computes gas transfer velocity from normalized radar backscatter are given in Frew et al. (2006). For purposes of discussion, a brief description of the algorithm is provided here.

Jackson et al. (1992) approximate the surface wave field as an isotropic, Gaussian wave field and apply the geometrical optics (GO) scattering model of Cox and Munk (1954) to relate radar backscatter to mean square slope. The availability of dual frequency radar data from TOPEX allows us to isolate a specific wavenumber region of the surface slope spectrum. In order to remove the contribution to backscatter from longer wavelengths, we difference the $\left\langle s^{2}\right\rangle$ computed from the two wavelengths thereby isolating the $6.3 \mathrm{~cm}$ to $16.5 \mathrm{~cm}(40-100 \mathrm{rad} / \mathrm{m})$ portion of the surface wave field. This differenced mean square slope is given by:

$$
\left\langle s^{2}\right\rangle_{40}^{100}=\frac{\rho_{n}^{\prime}(\mathrm{Ku})}{\sigma_{\mathrm{Ku}}^{\circ}}-\frac{\rho_{n}^{\prime}(\mathrm{C})}{\left(\sigma_{\mathrm{C}}^{\circ}+\alpha\right)},
$$

where $\left\langle s^{2}\right\rangle_{40}^{100}$ refers to the mean square slope of the $40-100 \mathrm{rad} / \mathrm{m}$ wavenumber portion of the surface wave field, $\rho_{n}^{\prime}$ are the wavelength specific, effective nadir reflectivities, and $\alpha$ is a correction term applied to the $\mathrm{C}$-band backscatter to account 
for the lack of an absolute calibration as reported in Chapron et al. (1995).

The field work of Frew et al. (2004), in coastal and offshore waters under low to moderate wind speeds, demonstrates that $k \propto\left\langle s^{2}\right\rangle$ and that, in the wavenumber range of $40-100 \mathrm{rad} / \mathrm{m}$, the relationship is quadratic:

$$
k_{\mathrm{T}}=\left[C_{0}+C_{1}\left(\left\langle s^{2}\right\rangle_{40}^{100}\right)^{2}\right]\left(\frac{\mathrm{Sc}(\mathrm{T}, \mathrm{S})}{660}\right)^{-\frac{1}{2}}
$$

where $k_{\mathrm{T}}$ is the in situ gas transfer velocity, $\mathrm{Sc}(\mathrm{T}, \mathrm{S})$ represents the Schmidt number at the sample temperature $\mathrm{T}$ and salinity $\mathrm{S}$, and the expression within the square brackets yields the transfer velocity at a Schmidt number of 660 , the $\mathrm{Sc}$ for $\mathrm{CO}_{2}$ in seawater at $20^{\circ} \mathrm{C}$ (Wanninkhof, 1992).

Frew et al. (2004) determine values for parameters $C_{0}$ and $C_{1}$ in Eqn 2 using data from the NSF sponsored Coastal Ocean Processes study in July 1997 (CoOP-97) in the northwest North Atlantic. The calibration and optimization of the other three parameters in our algorithm $\left(\rho_{\mathrm{Ku}}^{\prime}, \rho_{\mathrm{C}}^{\prime}\right.$ and $\left.\alpha\right)$ in Eqn 1 is done through a comparison of field and satellite $\left\langle s^{2}\right\rangle_{40}^{100}$ using CoOP-97 data (Frew et al., 2006).

Our algorithm incorporates the effect of sea surface films on gas transfer velocity via their moderating effect on mean square slope. The CoOP-97 field conditions included both open ocean and coastal observations, including waters impacted by surface films. However, the optimization carefully excluded observations with significant surface films as evidenced by surface enrichments of colored dissolved organic matter (Frew et al., 2004, 2006). This allowed unbiased indexing of both satellite and ground $\left\langle s^{2}\right\rangle_{40}^{100}$ observations with $U_{10}$ in the optimization procedure.

A multiobjective, goal attainment optimization routine "fgoalattain", from MathWorks (2000), estimates $\rho_{\mathrm{Ku}}^{\prime}, \rho_{\mathrm{C}}^{\prime}$, and $\alpha$ via sequential quadratic programming. This multiobjective, goal attainment optimization routine employs three objective goals: force the reduced chi-squared $\left(\chi_{\nu}^{2}\right)$ to have a value of one (Davis, 1986), force the $\left\langle s^{2}\right\rangle_{\text {satellite }} v s .\left\langle s^{2}\right\rangle_{\text {field }}$ relationship to be linear with a slope of one and an intercept of zero. Results for all algorithm parameters are summarized in Table 1.

\section{Results}

\subsection{Side-A to Side-B Transition}

The above calibration and optimization use CoOP-97 data as ground truth and perforce use data from the TOPEX Side-A altimeter. The consistency of the algorithm across the transition from the Side-A to the Side-B altimeter (February 1999) was 
ensured by performing the following analysis. The results in Fig. 1a and b show a monthly time series of the global, area-weighted averages of $\sigma_{\mathrm{Ku}}^{\circ}$ and $\sigma_{\mathrm{C}}^{\circ}$. On inspection of these plots, it seems plausible that the calibration developed from Side-A data can be applied to Side-B because there are no statistically significant differences across the Side-A/B transition when the variables are considered in isolation $\left(\Delta \sigma_{\mathrm{Ku}}^{\circ}(\mathrm{A}-\mathrm{B})=-0.02 \mathrm{~dB} ; \Delta \sigma_{\mathrm{C}}^{\circ}(\mathrm{A}-\mathrm{B})=0.03 \mathrm{~dB}\right)$. Quartly (2000) suggests the need for regular monitoring of the changing relationship between the two frequencies $\left(\sigma_{\mathrm{Ku}}^{\circ}-\sigma_{\mathrm{C}}^{\circ}\right)$. Due to the difference of inverses nature of our algorithm (Eqn 1), a change in the relative relationship between the $\mathrm{Ku}-$ and $\mathrm{C}$-bands across the Side-A — Side-B transition is very apparent (Fig. 1c and d).

Unfortunately insufficient field data exists to perform a calibration on the Side-B altimeter. The fact that the C-band altimeters on both Side-A and Side-B of TOPEX have no absolute calibration (Chapron et al., 1995) is exploited by adjusting the $\alpha$ parameter alone to account for the changed relationship between the $\mathrm{Ku}-$ and $\mathrm{C}$ band $\sigma^{\circ}$ of sides A and B. In Fig. 2 it is assumed that all of the offset evidenced in the linear trends of Side-A and Side-B can be compensated with a small change in $\alpha$. A new parameter $\left(\alpha_{\mathrm{B}}\right)$ is introduced for the Side-B data only and distinguished from the $\alpha$ found in the original optimization for the Side-A data $\left(\alpha_{\mathrm{A}}\right)$. The parameter $\alpha_{\mathrm{B}}$ is determined by postulating that the two linear trends must intersect at the transition (end of January 1999 - beginning of February 1999). To achieve an unbiased result, the same number of data points are used from both sides over annual cycles only (i.e., Side-A January 1994 through January 1999 and Side-B February 1999 through February 2004). Note that there is no change in the slope of the linear trends (they are statistically indistinguishable and consequently introduce no bias in $k$ with this approach) and that $\alpha_{\mathrm{A}}$ increases only $+3 \%\left(\alpha_{\mathrm{B}}=3.72\right)$. The new Side-B ad hoc calibration parameter is applied to the Side-B data and the results are plotted in Fig. 1e; see also Table 1.

\subsection{Jason-1}

The launch of Jason-1 (December 2001) into exactly the same orbit as TOPEX marked the beginning of a six-month intercalibration experiment between the two satellites one month later (January 2002). This experiment is known as the collinear phase of the Tandem Mission (two altimeters in orbit at the same time). It also represents a unique opportunity to evaluate algorithm precision. During the collinear phase Jason-1 and TOPEX were in the same orbit, looking at the same ground track, 73 seconds apart in time thus providing essentially duplicate measurements of surface roughness. Collocated $\sigma^{\circ}$ data (Ku- and $\mathrm{C}$-band) for both satellites were matched after removing those over land, clouds or shallow oceans. A separate analysis between TOPEX and Jason- $1 \sigma^{\circ}$ was performed $\left(\Delta \sigma_{\mathrm{Ku}}^{\circ}(\mathrm{T}-\mathrm{J})\right)=-2.39 \mathrm{~dB}$; $\left.\Delta \sigma_{\mathrm{C}}^{\circ}(\mathrm{T}-\mathrm{J})=-0.73 \mathrm{~dB}\right)$ to remove any biases between the two satellite instruments (Frew et al., 2006). Figure 3 shows the resultant transfer velocities obtained 
by applying the Side-B algorithm to both data streams. An analysis of the spread in these data points by both principal component analysis (Davis, 1986) and type-II linear regression (York, 1966) indicates that the precision of our Side-B algorithm is between 5 and $7 \%$ and scales with $k$. Furthermore the slope of the type-II linear regression indicates that Jason-1 estimates of $k$ are, on average, approximately 4\% higher than the estimates of $k$ from the Side-B altimeter onboard TOPEX when looking at the same spot on the ground 73 seconds later.

This last result might suggest that another analysis be done to calculate an ad hoc calibration parameter $\left(\alpha_{\mathrm{J} 1}\right)$ for use with Jason-1 data only. Unfortunately there is no convenient tie point (such as the beginning of February 1999 used for the Side$\mathrm{A} / \mathrm{B}$ transition) where this analysis can be done. One could allow the two collinear phase mean $\left\langle s^{2}\right\rangle_{40}^{100}$ be equal and calculate what this proposed $\alpha_{\mathrm{J} 1}$ would be. However, without independent field data $\left(\left\langle s^{2}\right\rangle\right)$ to corroborate such a calculation, we feel it is not prudent to use what is essentially a correction on a correction. When additional field data can be obtained to further calibrate and optimize the algorithm parameters, the small discrepancy between TOPEX Side-B and Jason-1 can be corrected (currently there is no statistically significant difference between the two time series means although there is an apparent bias).

\subsection{A 12-year time series}

Figure 4 shows the entire 12-year time series (note that January and February 1993 data are not available because the magnetic tapes storing this data degraded before the GCPc reprocessing could be performed and put online). This figure summarizes the latitudinal variation of the transfer velocity by plotting the zonally averaged means $v s$. the date they were measured. The features apparent in this plot are similar to those introduced in the Glover et al. (2002) algorithm. That algorithm assumed a linear $k=f\left(\left\langle s^{2}\right\rangle\right)$ relationship and used preliminary estimates of algorithm parameters. The range of $k$ values in Fig. 4, however, is greater due to the quadratic dependency in the new algorithm.

With Fig. 4 the pattern of overall seasonal variation is clear e.g., the maximum transfer velocities are in each hemisphere's corresponding wintertime. Along the equator there is an anti-correlated period of low to very low transfer velocities and at northern mid-latitudes $\left(20^{\circ}-40^{\circ} \mathrm{N}\right)$ there are summertime low transfer velocities. However, at similar southern latitudes low austral summertime transfer velocities do not appear in any year. The greater fetch at these latitudes, when compared to the northern hemisphere, is one possible explanation. The June 2004 results are anomalous in this respect and are due to a TOPEX safehold that lasted the first half of the month. Interestingly the 1997-1998 El Niño is not obvious in Fig. 4. This is probably due to the global nature of each zonal average, which are not areaweighted in this figure. 
Figure 4 can be collapsed along the latitude axis to form a climatology of the zonal distribution of transfer velocity as shown in Fig. 5. The nearly 12-year time series displays a symmetrical pattern of higher transfer velocities poleward with the highest between $50^{\circ}-60^{\circ} \mathrm{S}$. A reasonable explanation is that at these latitudes the fetch is greatest, whereas to the north land breaks up the fetch and farther to the south the air-sea interface is covered by the seasonal ice-pack. The absolute minimum is found at the equator with asymmetric shoulders extending poleward. The northern shoulder has a distinct local minimum in $k$ at approximately $25^{\circ} \mathrm{N}$, which corresponds to the summertime low transfer velocities seen in Fig. 4. The northernmost latitudes in Fig. 5 appear noisier than at similar southern latitudes possibly due to the lack of a circumpolar current in the northern hemisphere.

The data of Fig. 4 can also be collapsed along the time axis as Fig. 6. Since each grid point is defined as a $2.5^{\circ}$ square, the data points in Fig. 6 represent areaweighted averages at each point in time. Results from the nearly 12-year time series of TOPEX Side-A and -B altimeters are shown along with the results from Jason-1 processed with the $\alpha_{\mathrm{B}}$ parameter in section 3.1. It is interesting to note the apparent dominance of the northern hemisphere in this time series. Careful inspection of Fig. 4 reveals that although the southern hemisphere has a more persistent high transfer velocity throughout the year, Fig. 6 also averages the anticorrelated low $k$ at mid-latitudes in the northern hemisphere into the global, area-weighted mean during the austral winter. There is a statistically significant linear trend present in the TOPEX record amounting to $+6.7 \times 10^{-2} \mathrm{~cm} \mathrm{~h}^{-1} \mathrm{y}^{-1}$. The close agreement between TOPEX Side-B and Jason-1 is interrupted only once in June 2004. During June 2004 TOPEX was placed in a safehold mode during cycles 431 (26 May 2004) through 432 due to a roll reaction wheel failure; normal operation of TOPEX did not resume until 17 June 2004 (cycle 433). The means of TOPEX Side-B and Jason transfer velocities are not statistically different at the $95 \%$ confidence level. Therefore one may conclude that the transition to Jason- 1 for continuing the time series does not present any technical problems at this time.

\section{Summary}

An algorithm which computes $k=f\left(\sigma_{\mathrm{Ku}}^{\circ}, \sigma_{\mathrm{C}}^{\circ}\right)$ via $\left\langle s^{2}\right\rangle$ has been applied across three separate dual frequency altimeters to form a nearly 12 -year time series. The long term, global, area-weighted mean gas transfer velocity $\left(\left\langle k_{660}\right\rangle\right)$ of the time series is $16 \mathrm{~cm} / \mathrm{h}$. This compares favorably with the Wanninkhof et al. (2002) estimate of $17-18 \mathrm{~cm} / \mathrm{h}$ and represents an improvement over the $13 \mathrm{~cm} / \mathrm{h}$ reported by Glover et al. (2002). The algorithm has a precision of approximately 5-7\%, which scales with the magnitude of $k$. A careful inspection of the collinear phase of the TOPEX - Jason-1 Tandem Mission shows that there is an approximate $4 \%$ bias in favor of Jason-1 estimates of $k$. The close agreement seen between TOPEX Side-A and Side-B altimeters and between TOPEX Side-B and Jason-1 altimeters strongly 
implies that a decadal to multi-decadal time series of $k$ is now possible.

There are several caveats to bear in mind in applying our algorithm. First, the calibration and optimization of the algorithm are based on a relatively limited set of field observations made during CoOP-97 (Frew et al., 2004). Although that experiment included observations from both coastal and oligotrophic waters, the generalization to the global ocean is tentative and would benefit from a wider geographic observation base. Second, mean square slope measurements at higher winds are difficult to make and relatively few measurements of $\left\langle s^{2}\right\rangle_{40}^{100}$ at high wind speeds are available. The mean square slope and gas transfer velocity observations made during CoOP-97 were limited to wind speeds of $<10 \mathrm{~m} / \mathrm{s}$. The behavior of smallscale wave slope as wind speed increases above $10 \mathrm{~m} / \mathrm{s}$ is thus uncertain, as is the dependence of $k$ on $\left\langle s^{2}\right\rangle_{40}^{100}$; the algorithm is therefore an extrapolation for higher winds. Third, the algorithm does not explicitly include a physics-based formulation of bubble-mediated effects due to breaking waves (Woolf, 2005), which may be significant for relatively insoluble gases. It assumes a Schmidt number exponent $n=-0.5$ (c.f. Eqn. 2), which may not apply at higher wind speeds, when bubble effects can be significant. We note however that the algorithm may implicitly include a breaking wave contribution as evidenced by a distinct change in the sensitivity between the $\mathrm{C}$-band and $\mathrm{Ku}$-band normalized backscatter to increasing sea surface roughness at winds above $\sim 7 \mathrm{~m} / \mathrm{s}$, possibly associated with the onset of boundary layer flow separation and wave breaking events (Chapron et al., 1995; Banner and Melville, 1976). Clearly, further validation and refinement of the algorithm will benefit from additional field measurements of mean square slope and transfer velocities under a wider range of forcing conditions than has been previously reported.

\section{Acknowledgements}

The authors thank an anonymous reviewer for his/her helpful critique of an earlier manuscript. We gratefully acknowledge funding support from NASA under grant NAGW-2431 and JPL contract 961425 . Monthly images and data sets are available at:

http://w3eos.whoi.edu/ david/ktrans/img_dat.html

\section{References}

Banner, M. L. and W. K. Melville, 1976, On the separation of air-flow over water waves, J. Fluid Mech., 77, 825-842.

Benada, J.R., 1997, Merged GDR (TOPEX/Poseidon) Generation B User's Handbook, Version 2.0, D-11007, 124 pp., Physical Oceanography Distributed Active Archive Center (PO.DAAC), Jet Propulsion Laboratory, California Institute of Technology. 
Bock, E.J., T. Hara, N.M. Frew, and W.R. McGillis, 1999, Relationship between air-sea gas transfer and short wind waves, J. Geophys. Res., 104, 25821-25831.

Chapron, B., K. Katsaros, T. Elfouhaily, and D. Vandemark, 1995, A note on relationships between sea surface roughness and altimeter backscatter, In: Air-Water Gas Transfer, Selected Papers from the Third International Symposium on AirWater Gas Transfer July 24-27, 1995, Heidelberg University, B. Jähne and E.C. Monahan (eds.), AEON Verlag \& Studio, Hanau, pp 869-878.

Cox, C. and W. Munk, 1954, Statistics of the sea surface derived from sun glitter, J. Mar. Res., 13(2), 198-227.

Davis, J.C., 1986, Statistics and Data Analysis in Geology. John Wiley and Sons, New York, 646pp.

DeGrandpre, M.D., G.J. Olbu, C.M. Beatty, and T.R. Hammar, 2002, Air-sea $\mathrm{CO}_{2}$ fluxes on the U.S. Middle Atlantic Bight, Deep-Sea Res., 49, 4355-4367.

Frew, N. M, E. J. Bock, U. Schimpf, T. Hara, H. Haußecker, J. B. Edson, W. R. McGillis, R. K. Nelson, S. P. McKenna, B. M. Uz, and B. Jähne, 2004, Air-sea gas transfer: Its dependence on wind stress, small-scale roughness and surface films, J. Geophys. Res., 109, C08S17, doi: 10.1029/2003JC002131.

Frew, N. M., D. M. Glover, E. J. Bock, and S. J. McCue, 2006, A new approach to estimation of global air-sea gas transfer velocity fields using dual-frequency altimeter backscatter, submitted to J. Geophys. Res.

Glover, D.M., N.M. Frew, S.J. McCue, and E.J. Bock (2002) A Multi-year Time Series of Global Gas Transfer Velocity from the TOPEX Dual Frequency, Normalized Radar Backscatter Algorithm, In: Gas Transfer at Water Surfaces, editors: M. Donelan, W. Drennan, E. Saltzman, and R. Wanninkhof, Geophysical Monograph 127, American Geophysical Union, Washington, DC, 325-331.

Jackson, F.C., W.T. Walton, D.E. Hines, B.A. Walter, and C.Y. Peng, 1992, Sea surface mean square slope from Ku-band backscatter date, J. Geophys. Res., 97(C7), $11,411-11,427$.

MathWorks, 2000, Optimization Toolbox, User's Guide version 2.1, The MathWorks Inc., Natick, MA, 332 pp.

Olsen, A., R. Wanninkhof, J.A. Triñanes, and T. Johannessen, 2005, The effect of wind speed products and wind speed-gas exchange relationships on interannual variability of the air-sea $\mathrm{CO}_{2}$ gas transfer velocity, Tellus, 57B, 95-106.

Picot, N., K. Case, S. Desai, and P. Vincent, 2003, AVISO and PODAAC User Handbook: IGDR and GDR Jason Products, SMM-MU-M5-OP-13184- CN (AVISO), JPL D-21352 (PODAAC).

Quartly, G.D., 2000, Monitoring and cross-calibration of altimeter $\sigma^{\circ}$ through dualfrequency backscatter measurements, J. Atmos. Oceanic Technol., 17, 12521258.

Tournadre, J. and J. Morland, 1997, The effects of rain on TOPEX/POSEIDON altimeter data, IEEE Trans. Geosci. Remote Sensing, 35, 1117-1135.

Wallace, D.W.R., 1995, Monitoring global ocean carbon inventories, OOSDP Background Report Number 5, 54 pp, Ocean Observing System Development Panel, Texas A\&M University, College Station, TX.

Wanninkhof, R., 1992, Relationship between wind speed and gas exchange over 
the ocean, J. Geophys. Res., 97, 7373-7382.

Wanninkhof, R., S.C. Doney, T. Takahashi, and W.R. McGillis, 2002, The effect of using time-averaged winds on regional air-sea CO2 fluxes, in: Gas Transfer at Water Surfaces, ed. M. Donelan, W. Drennan, E. Saltzman, and R. Wanninkhof, Geophysical Monograph 127, Washington, DC, pp. 351-357, AGU.

Woolf, D.K., 2005, Parameterization of gas transfer velocities and sea- statedependent wave breaking, Tellus, 57B, 87-94.

York, D., 1966, Least-squares fitting of straight lines, Canad. J. Phys., 44, 10791086. 
Table 1

\begin{tabular}{|c|c|}
\hline \multicolumn{2}{|c|}{ Algorithm parameters } \\
\hline parameter & value \\
\hline$C_{\circ}$ & 1.4 \\
$C_{1}$ & $7.58 \times 10^{5}$ \\
$\rho_{\mathrm{Ku}}^{\prime}$ & 0.427 \\
$\rho_{\mathrm{C}}^{\prime}$ & 0.617 \\
$\alpha_{\mathrm{A}}$ & 3.61 \\
$\alpha_{\mathrm{B}}$ & 3.72 \\
\hline
\end{tabular}




\section{List of Figures}

Figure 1: The global, monthly, area-weighted average a) $\sigma_{K u}^{\circ}$, b) $\sigma_{C}^{\circ}$, c) $\sigma_{C}^{\circ}-\sigma_{K u}^{\circ}$, d) $1 /\left(\sigma_{C}^{\circ}-\sigma_{K u}^{\circ}\right)$, and e) $\left\langle s^{2}\right\rangle_{40}^{100}$. As can be seen in these diagnostic plots subtle differences between the relative performance of the $\mathrm{Ku}$ - and $\mathrm{C}$ - band altimeters are not obvious until the results are differenced.

Figure 2: The global, monthly, area-weighted time series of $\left\langle s^{2}\right\rangle_{40}^{100} v s$. time before calculation of $\alpha_{\mathrm{B}}$. The step discontinuity is clearly visible as TOPEX transitions from the Side-A to the Side-B altimeter at the beginning of February 1999.

Figure 3: A plot of all of the TOPEX Side-B vs. Jason-1 estimates of $k$ from the collinear phase of the Tandem Mission. A type-II regression indicates that there is a slight bias between TOPEX and Jason-1, but it does not exceed 4\%. The probability density function contours are plotted to show the distribution of the 6.4 million data points in this plot and the dashed line is the 1:1 line for reference.

Figure 4: The monthly zonal average time series (1993-2005) of the TOPEXderived gas transfer velocities plotted as their latitude $v s$. time. The minimum value is approximately $5 \mathrm{~cm} / \mathrm{hr}$.

Figure 5: Transfer velocity as a zonal function of latitude. Each zone is $2.5^{\circ}$ in latitude.

Figure 6: The monthly, area-weighted, average time series (1993-2005) of the TOPEX-derived gas transfer velocities plotted as a function of time. The longterm, area-weighted mean $k$ is $16 \mathrm{~cm} / \mathrm{hr}$. The Jason-1 results (beginning with January 2002) are plotted as the thin black line over the thicker gray line representing the TOPEX results from both Side-A and -B. 
TOPEX cycle no.
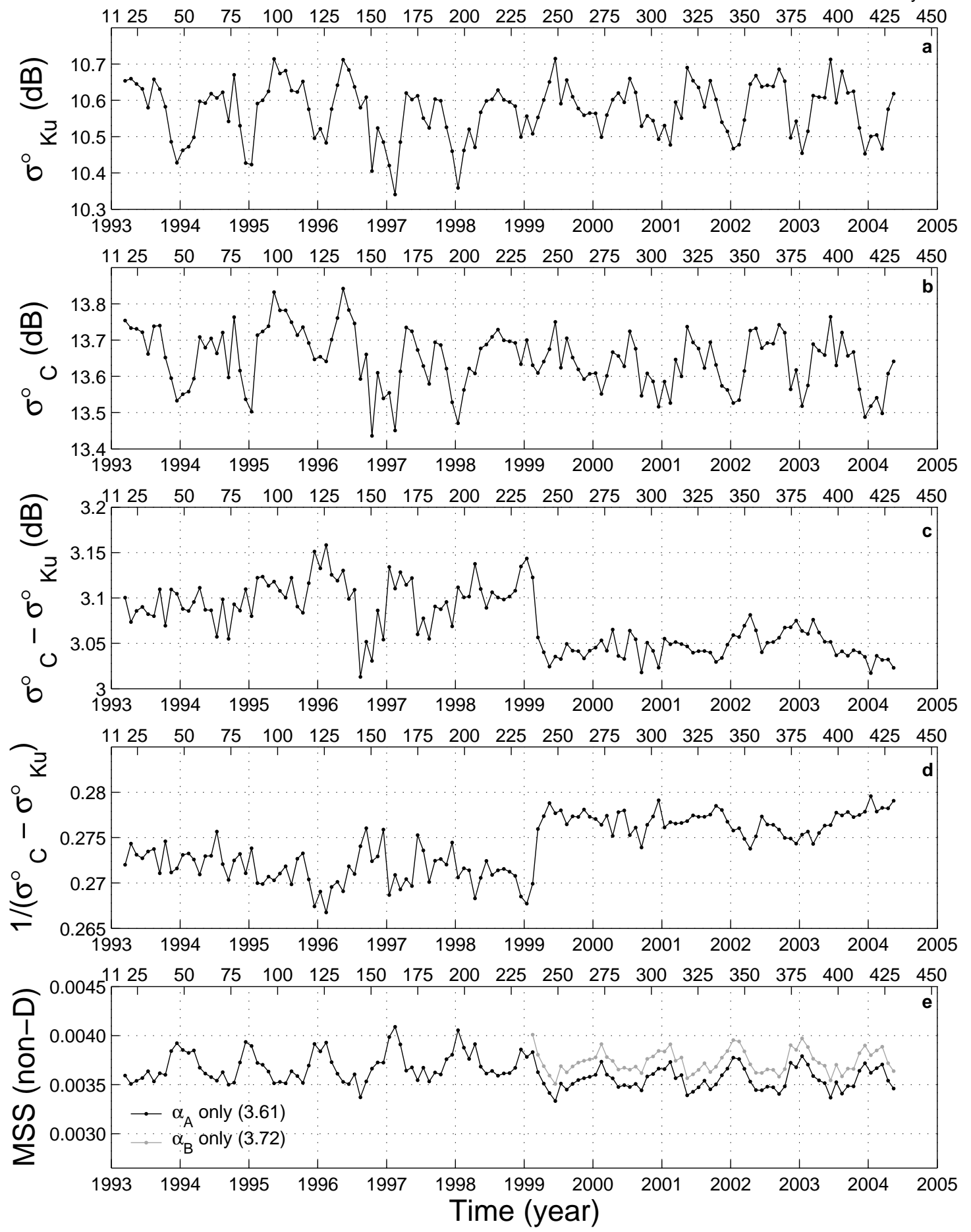

Fig. 1. ./figures/plt_reg_zonavg_reconcile_redoAB3tJMS.eps 


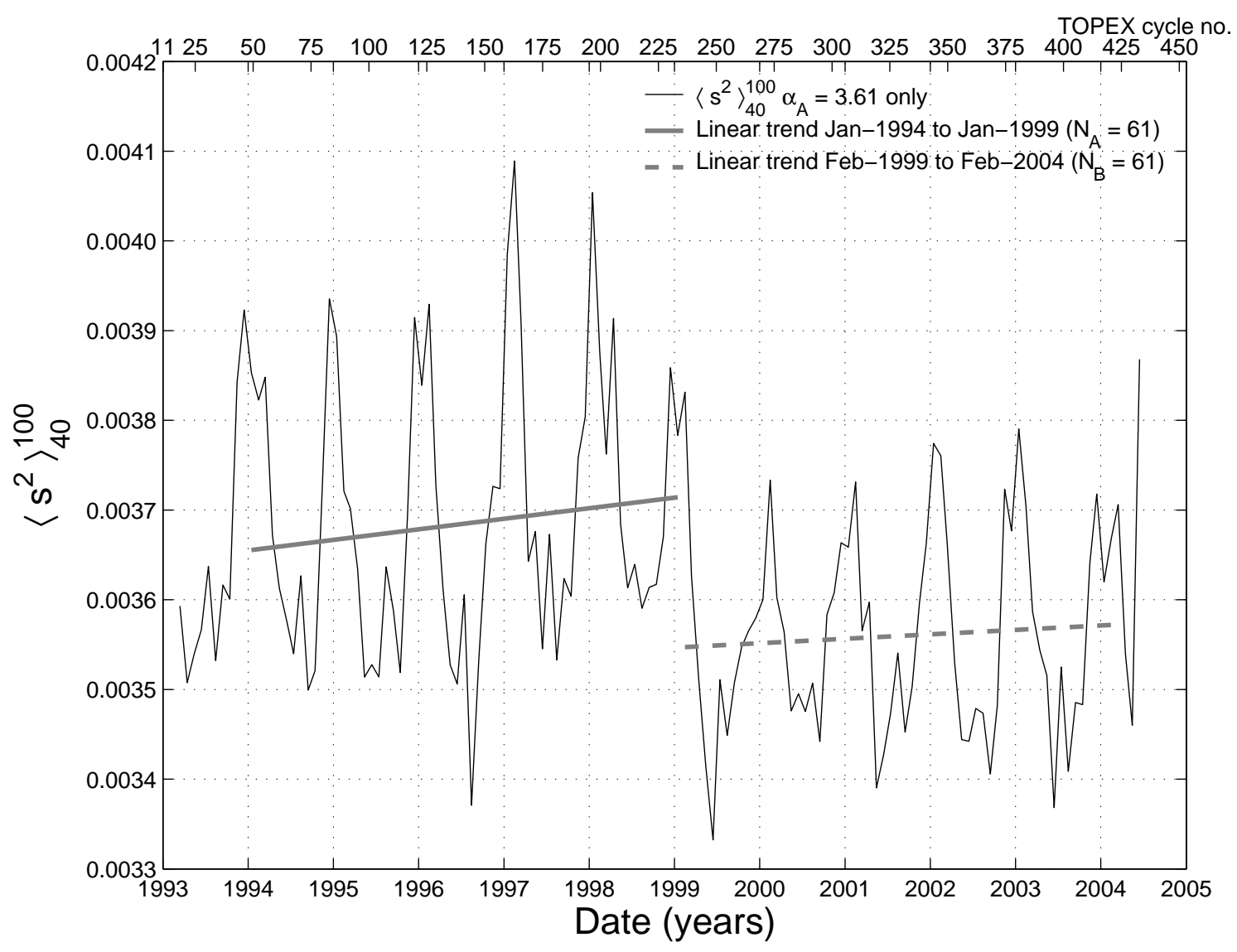

Fig. 2. ./figures/calc_alpha_B_JMS.eps 


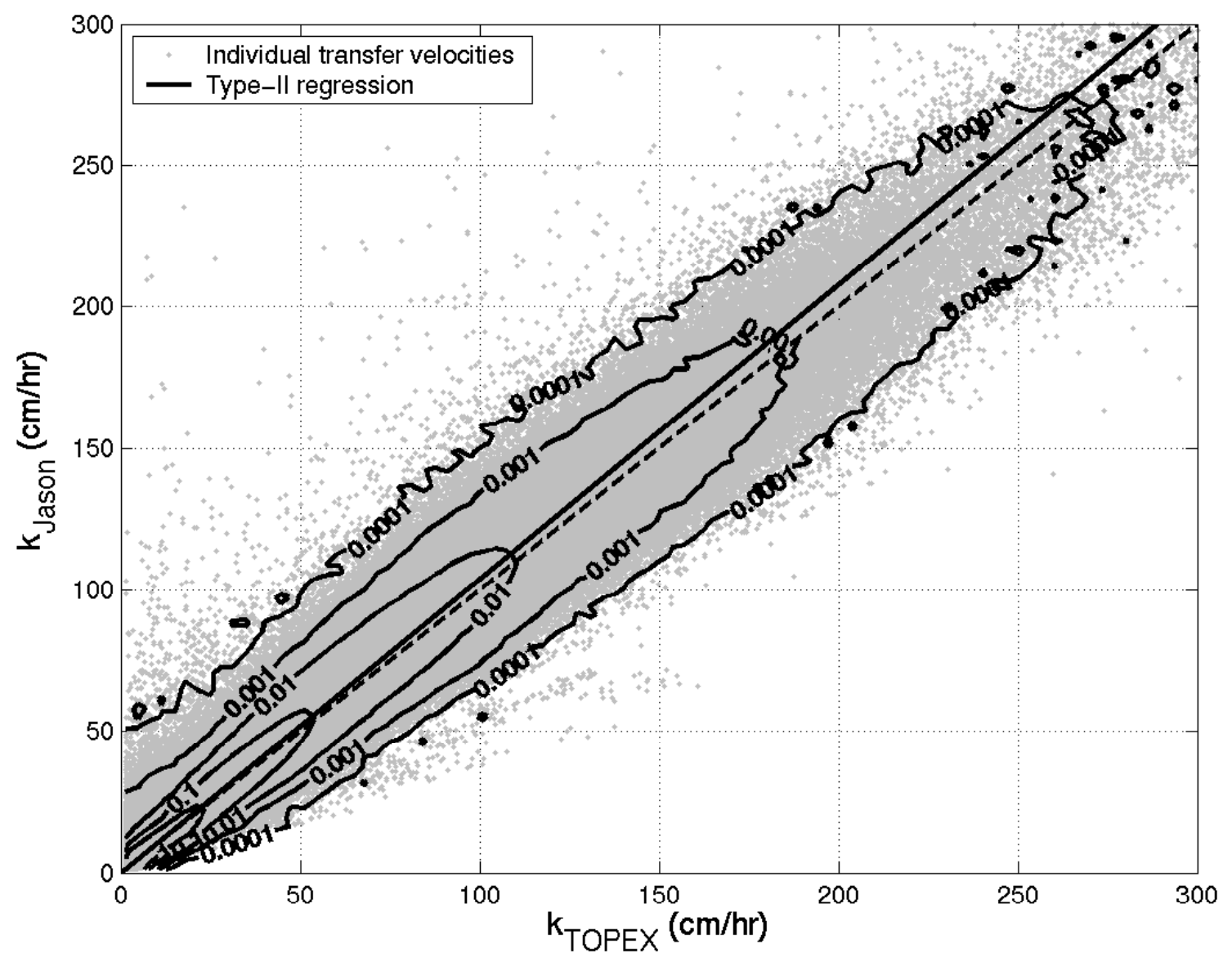

Fig. 3. ./figures/k_lt300_JMS.eps 


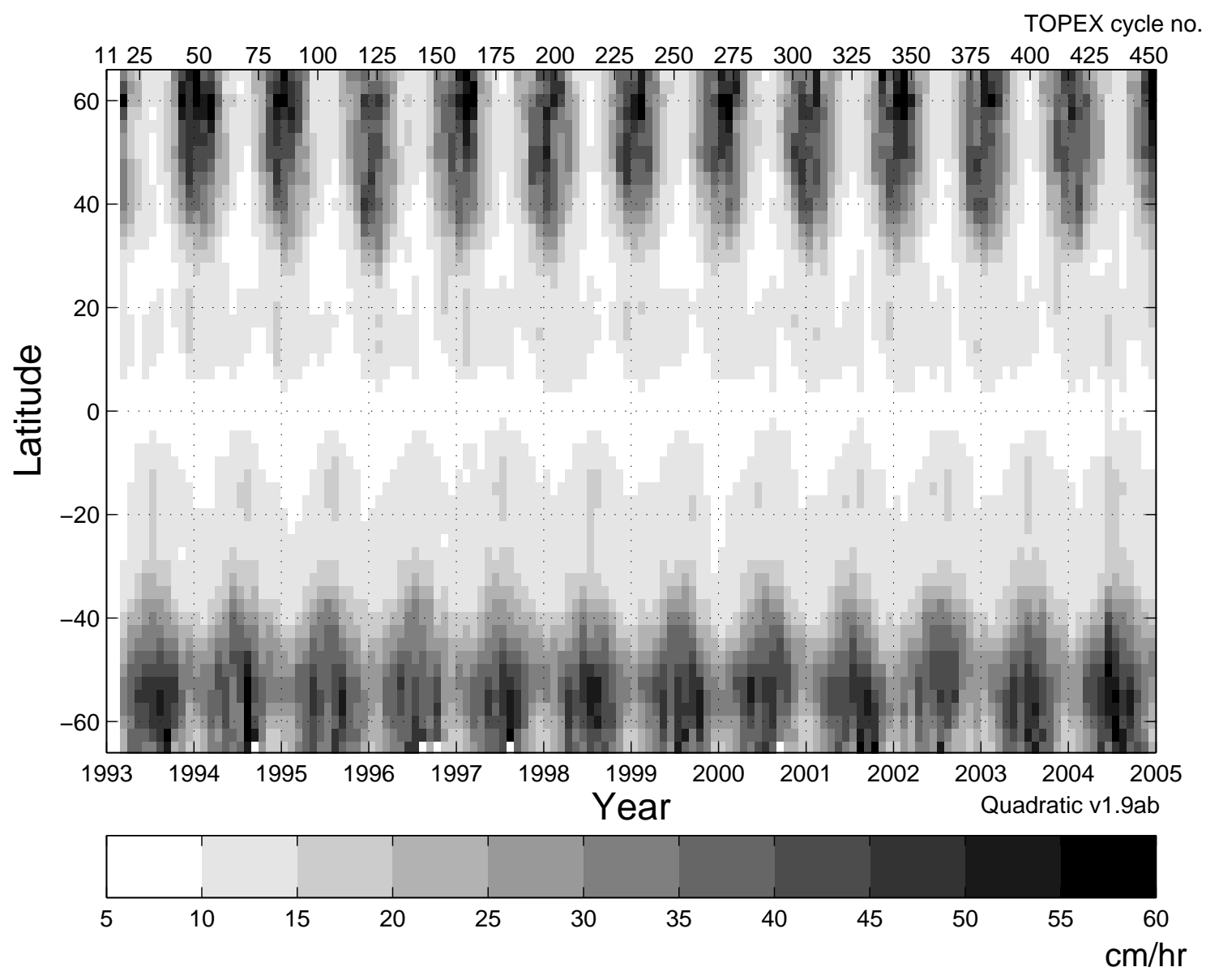

Fig. 4. ./figures/zon_avg_FGB1p9abJMS.eps 


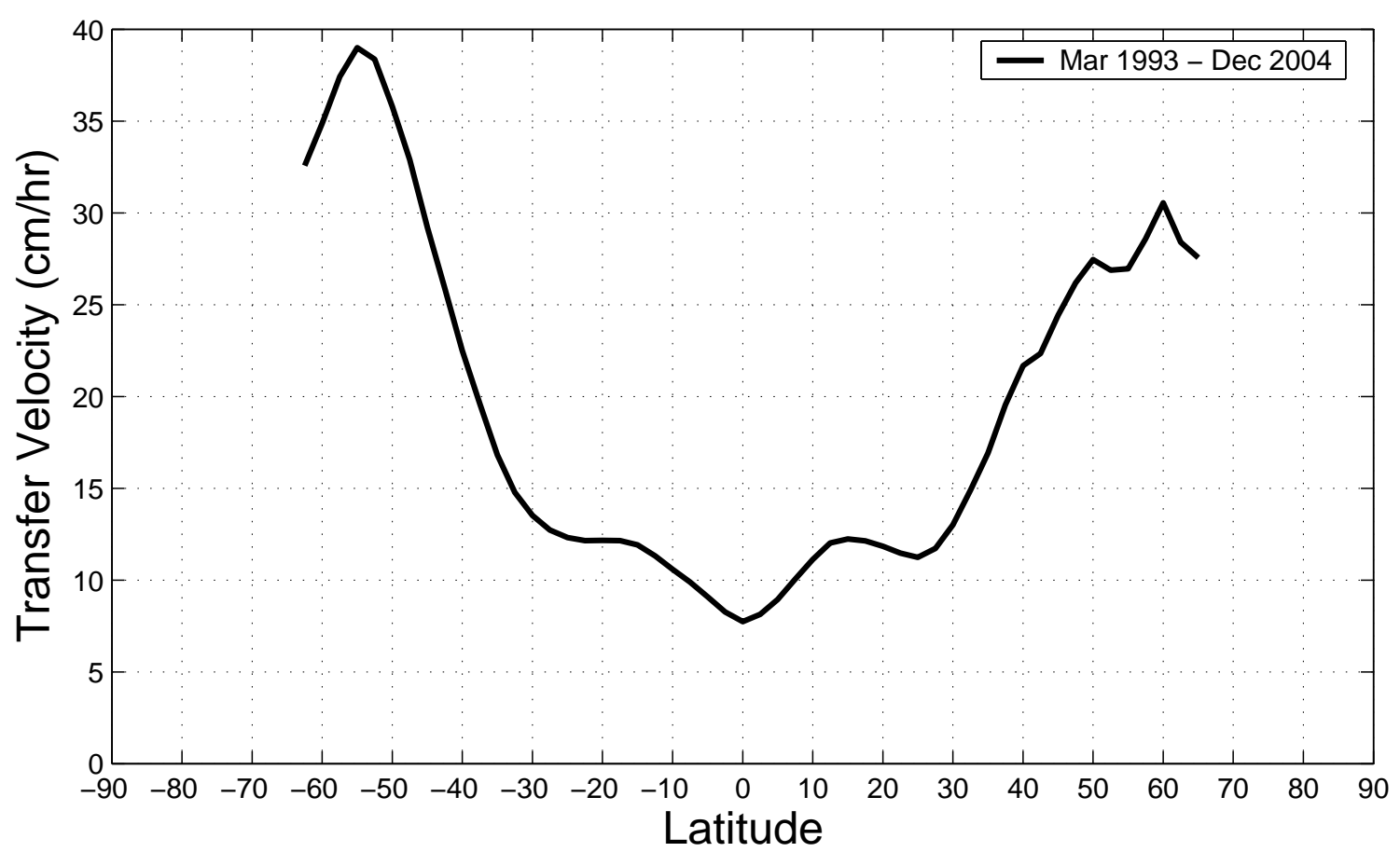

Fig. 5. ./figures/plt_reg_zonavg_gcpc_1p9ab_globalJMS.eps

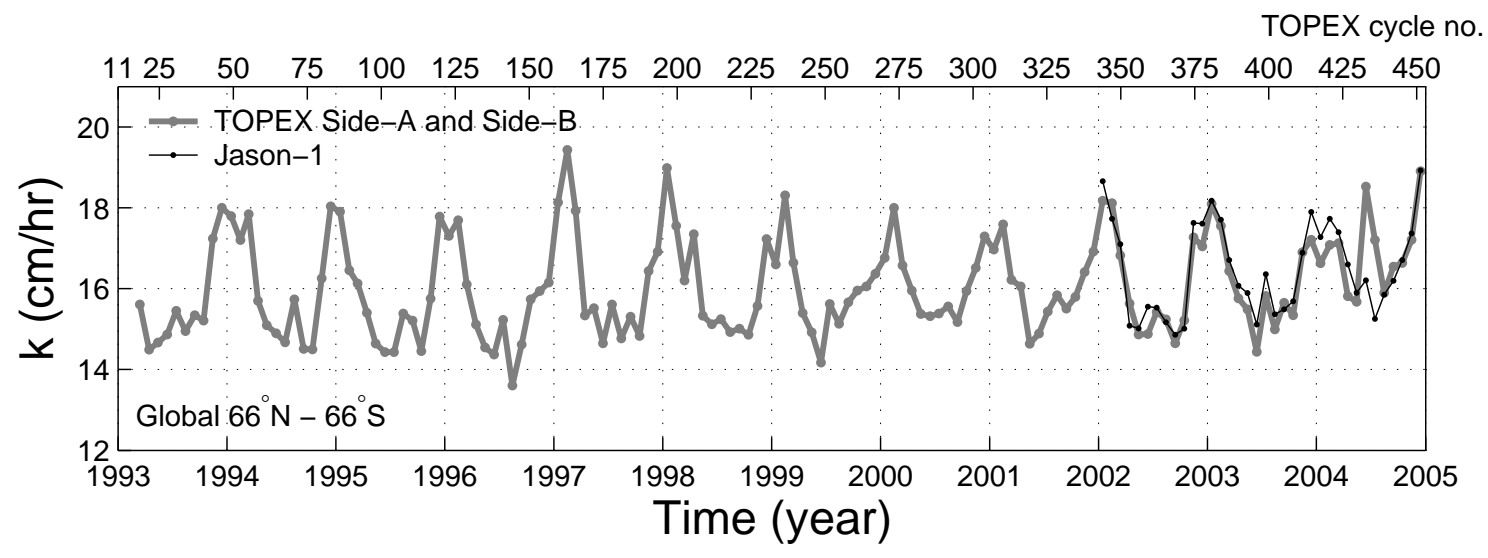

Fig. 6. ./figures/plt_reg_zonavg_gcpc_1p9b3tJMS.eps 